\title{
X-ray diffraction line profile analysis of nanostructured nickel oxide: Shape factor and convolution of crystallite size and microstrain contributions
}

\author{
K. Maniammal ${ }^{\mathrm{a}}$, G. Madhu ${ }^{\mathrm{b}}, \mathrm{V}$. Biju, ${ }^{\mathrm{a}, *}$ \\ a Department of Physics, University of Kerala, Kariavattom Campus, \\ Thiruvananthapuram, Kerala, Pin - 695581, INDIA \\ ${ }^{\mathrm{b}}$ Department of Physics, University College, Thiruvananthapuram, Kerala, Pin-695034, INDIA \\ *Corresponding author. Tel: +91 4712308920 E-mail:- bijunano@gmail.com
}

\begin{abstract}
Nanostructured nickel oxide is synthesized through a chemical route and annealed at different temperatures. Contribution of crystallite size and microstrain to X-ray diffraction line broadening are analyzed by Williamson- Hall analysis using isotropic and anisotropic models. None of the models perform well in the case of samples with smaller average crystallite sizes. For sample with crystallite size $\sim 3 \mathrm{~nm}$ all models show negative slope which is physically meaningless. Analysis of shape factor shows that the line profiles are more Gaussian like. Sizestrain plot method, which assumes a different convolution of the crystallite size and microstrain contributions, is found to be most suitable. The study highlights the fact that the convolution of crystallite size and microstrain contributions may differ for samples and should be taken into account while analyzing the observed line broadening. Microstrain values show a regular decrease with increase in the annealing temperature.
\end{abstract}

Key words: defects; X-ray diffraction; microstrain; line broadening; shape factor; nanostructured materials. 


\section{Introduction}

The physical and chemical properties of nanocrystalline materials are markedly different from those of single crystalline and coarse grained polycrystalline samples with the same average chemical composition [1]. Numerous studies on the structure-property correlations in nanostructured samples of varied types have appeared in the literature. Large surface areas to volume ratio and quantum size effects are the most important factors that determine the varied physical and chemical properties of nanocrystalline materials $[1,2]$. However, there are other factors such as lattice strain, compensation at the surface, non-stoichiometry, etc., which could also contribute to the varied properties.

Lattice strain, which is one of the important structural parameters that could influence the physical properties, can be studied using X-ray diffraction (XRD) technique [3]. Two types of lattice strains are associated with nanocrystalline materials [4, 5]. First kind extends over the entire lattice and is manifested as a shift in the position of the XRD peaks while the second kind extends only over a few lattice spacings and is often referred to as 'microstrain' or 'localized lattice strain' [6]. Microstrain originates due to the presence of defects such as vacancies or cores of vacancies in the lattice, excess fraction of grain boundaries, etc., and causes broadening of the XRD peaks $[2,5-7]$. Thus microstrain is a measure of the concentration of defects in the sample. In the case of systems such as nanostructured transition metal oxides where the presence, concentration and distribution of cation/anion vacancies could precipitously affect the physical and chemical properties, microstrain could be used as an indirect measure of the 
concentration of defects in the sample and hence could be a useful structural parameter for structure-property correlation $[2,6]$.

From this discussion, it is clear that in the case of nanostructured samples, XRD line broadening could have contribution from both small crystallite size and microstrain [8]. A number of analytical methods are suggested for separating the crystallite size and microstrain contributions to the XRD line broadening, viz., Williamson-Hall method, Warren-Averbach method, Fourier method, Rietveld refinement, etc [8-11]. Though full pattern refinement techniques are more rigorous, the execution is very complex due to a large number of control parameters and hence techniques such as Williamson-Hall analysis and Warren-Averbach procedures are often employed. Warren-Averbach method requires at least two orders of reflections along each crystallographic direction and when higher order reflections are weak and difficult to analyze Williamson-Hall method is employed [12]. Williamson-Hall method assuming uniform deformation (UDM) in all directions is computationally simple and can be implemented conveniently [8]. Also, the anisotropic nature of the elastic constants of the crystal can be incorporated in the Williamson-Hall analysis by using uniform deformation stress (UDSM) or uniform deformation energy density (UDEDM) models [8, 12, 13]. A number of reports on the Williamson-Hall analysis of nanostructured samples of different kinds have appeared in the literature in the recent past $[6,12-23]$. A perusal of these reports reveals that models which take into account the anisotropic nature of the crystal, viz., UDSM and UDEDM often more correctly model the system than the one which does not take the anisotropy into account viz., UDM [6, 13-17,20]. Further, it was also noted that in the case of samples with smaller crystallite sizes, less than $\sim 10 \mathrm{~nm}$, the scattering of the points about the linear fit was 
markedly more, implying low value for correlation coefficient [3, 19-20]. For samples with larger average crystallite sizes the correlation is usually very high $[6,12]$.

Recently Madhu et al., had reported the Williamson-Hall analysis of nanocrystalline nickel oxide $(\mathrm{NiO})$ samples synthesized through a wet chemical route with crystallite size in the range $33-50 \mathrm{~nm}$ and had inferred that the presence of both $\mathrm{Ni}^{2+}$ and $\mathrm{O}^{2-}$ vacancies contribute to microstrain [6]. It was shown that the microstrain values together with conductivity measurements/antioxidant activity could provide information on the relative concentration of $\mathrm{Ni}^{2+}$ and $\mathrm{O}^{2-}$ vacancies. In general, nanostructured $\mathrm{NiO}$ may contain both $\mathrm{Ni}^{2+}$ and $\mathrm{O}^{2-}$ vacancies and their relative concentration is important in determining the optical, electrical, magnetic, electrochemical, catalytic, etc., properties. Hence in the case of nanostructured $\mathrm{NiO}$ microstrain could be an important parameter in determining the structure-property correlation. This paper compares the performance of the isotropic and anisotropic models of Williamson-Hall analysis in the case of nanocrystalline $\mathrm{NiO}$ samples with average crystallite sizes in the range $\sim 2-22 \mathrm{~nm}$ synthesized through chemical method. It may be noted that the size range is much smaller in comparison with previous reports [6]. A comparison of the performance of the different models (isotropic and anisotropic) in the case of samples with very small average crystallite size, $<10$ $\mathrm{nm}$ is interesting. Size-strain plot analysis which is a modified form of the Williamson-Hall concept, assuming a different convolution of size and microstrain contributions to XRD line broadening, is also done and the performance is compared with those of the conventional isotropic and anisotropic models. 


\section{Experimental}

Nanostructured nickel oxide $(\mathrm{NiO})$ was synthesized through a two step process. In the first step, nickel carbonate precursor was synthesized through a controlled chemical precipitation route using nickel chloride $\left(\mathrm{NiCl}_{2} \cdot 6 \mathrm{H}_{2} \mathrm{O}\right)$ and ammonium carbonate $\left(\mathrm{NH}_{4} \mathrm{CO}_{3}\right)$ as the starting materials and ethylene dinitrilo tetra acetic acid disodium salt (EDTA) as the stabilizer. All the chemicals used were of analytical grade and were used without further purification. The carbonate precursor was washed several times with distilled water and was dried in a hot air oven at $80^{\circ} \mathrm{C}$. In the second step, the finely powdered precursor was decomposed at $250^{\circ} \mathrm{C}$ for 2 hours in air ambience to get a loose powder of nanostructured NiO (sample code N1). The as prepared sample was annealed in air at different temperatures, viz., $350(\mathrm{~N} 2), 450$ (N3), 500 (N4), $600(\mathrm{~N} 5), 700(\mathrm{~N} 6)$ and $800^{\circ} \mathrm{C}(\mathrm{N} 7)$ for 1 hour each. The sample codes given in brackets will be used for convenience in the results and discussions section.

The XRD patterns of the samples were recorded using a Philips X'pert Pro diffractometer with $\mathrm{Cu} k \alpha(\lambda=1.54056 \AA)$ radiation in the $2 \theta$ range of $10-70^{0}$. The source was operating under an accelerating voltage of $40 \mathrm{kV}$ with a tube current of $30 \mathrm{~mA}$. Continuous scan was done with a scan step size of $0.08356^{\circ}$ and time per step 39.95 s. Transmission Electron Microscopic (TEM) analysis of two representative samples N1 and N4 were carried out using a Philips CM-200 Transmission Electron Microscope.

\section{Results and Discussion}

The XRD patterns of the samples are shown in Fig. 1 which can be indexed using JCPDS-ICDD Pattern number 47-1049 corresponding to $\mathrm{NiO}$ with cubic symmetry (space group-Fm3m (225)). The XRD lines are markedly broad indicating nanocrystalline nature. 
Further, the XRD lines become notably narrower with increase in the annealing temperature indicating an increase in the crystallite size. The as prepared sample (N1) is black in colour indicating nonstoichiometric nature with excess of uncompensated $\mathrm{Ni}^{2+}$ vacancies [24]. On annealing, the colour changes towards green and N7 is green indicating shift towards stoichiometry [24-28]. Thus, it is clear that on annealing together with an expected increase in the crystallite size there is a change in defect concentration and hence an analysis of the contributions of crystallite size and microstrain is interesting.

The full width at half maxima (FWHM), $\beta_{\text {obs }}$ for each diffraction peak was estimated by a curve fitting routine assuming a pseudo-Voigt function for the line profile. Before analyzing the contributions of small crystallite size and microstrain to the XRD line broadening, the instrumental contribution to the line width of each peak must be estimated and subtracted $[10$, 29, 30]. For this the XRD pattern of standard silicon sample was recorded under identical conditions and the width due to instrumental factors for each diffraction peak of $\mathrm{NiO}, \beta_{\text {ins }}(2 \theta)$ was estimated by a method already reported [29]. The XRD line broadening corrected for instrumental factors, $\beta_{\text {cor }}$ corresponding to each diffraction peak was estimated using the relation $\beta_{\text {cor }}=\left(\beta_{\text {obs }}^{2}-\beta_{\text {ins }}^{2}\right)^{1 / 2}[10]$. The FWHM value corrected for instrumental contribution was used for further analysis and will be referred to as $\beta_{\mathrm{hkl}}$ with hkl representing the Miller indices for each peak.

\subsection{Determination of crystallite size using Scherrer equation}

Scherrer equation is the simplest and most widely used method to estimate the average crystallite size from the XRD line broadening and is $t=k \lambda / \beta_{\mathrm{hkl}} \operatorname{Cos} \theta_{\mathrm{hkl}}$, where, $\mathrm{t}$ is the average crystallite size along the hkl direction, $\lambda$ is the wavelength of $\mathrm{X}$-rays used, $\beta_{\mathrm{hkl}}$ is the Full width 
at half maximum (FWHM) corrected for instrumental broadening, $\theta_{\mathrm{hkl}}$ is the diffraction angle and $\mathrm{k}$ is the shape factor lying between 0.9 and 1.15 [31]. This method has the limitation that microstrain contribution to line broadening is not taken into account and the entire line broadening is assumed to result from small crystallite size [32]. This assumption may lead to erroneous estimates of the crystallite size in situations where microstrain also contributes to line broadening [33]. The average crystallite sizes for the samples estimated using Scherrer equation are included in Table 1. The crystallite size mentioned for each sample is the average of those estimated from the three diffraction peaks and the deviation is the standard deviation among the sizes estimated from the peaks. The average crystallite size for sample N1 is $1.79 \pm 0.34 \mathrm{~nm}$ and with annealing it increases and is $21.62 \pm 0.23 \mathrm{~nm}$ for sample N7. Gradual increase in crystallite size with increase in annealing temperature is clear from Table 1. As already stated, there could be a contribution due to microstrain to the XRD line broadening over and above the small crystallite size and in the following two sections, the results of Williamson-Hall analysis and size-strain plot analysis for separating the crystallite size and microstrain contributions is presented.

\subsection{Williamson-Hall analysis}

According to Williamson-Hall method, the crystallite size and microstrain contributions to line broadening are respectively $\beta_{\mathrm{t}}=\mathrm{k} \lambda / \operatorname{tcos} \theta_{\mathrm{hkl}}$ and $\beta_{\varepsilon}=4<\varepsilon>\tan \theta_{\mathrm{hkl}}$ [34]. Here the size dependent part is same as in the case of Scherrer equation while in the strain dependent part, $<\varepsilon>$ is the r.m.s value of the microstrain in the sample which is assumed to be same in all crystallographic directions [8]. It is also assumed that the two contributions are independent of one another and are additive, i.e., $\beta_{\mathrm{hkl}}=\beta_{\mathrm{t}}+\beta_{\varepsilon}$ [35]. As the r.m.s microstrain is assumed to be 
the same in all crystallographic directions, this model does not take the anisotropic nature of the elastic constants of the crystal into account and is referred to as uniform deformation model (UDM). Williamson-Hall equation is written as $\beta_{\mathrm{hkl}} \cos \theta_{\mathrm{hkl}}=\mathrm{k} \lambda / \mathrm{t}+4<\varepsilon>\sin \theta_{\mathrm{hkl}}$ [8]. By plotting $\beta \cos \theta_{\mathrm{hkl}}$ versus $4 \sin \theta_{\mathrm{hkl}}$ and fitting the data with a linear relation, the r.m.s microstrain $<\varepsilon>$ can be estimated from the slope of the curve and average crystallite size from the Y- intercept [8]. As crystals are in general anisotropic, the elastic constant is bound to be direction dependent. Hence the assumption in UDM that the r.m.s microstrain has the same value in all crystallographic directions (i.e. for all peaks) is far from reality and could affect the performance. Hence Williamson-Hall method is to be improved by incorporating the anisotropic nature of the elastic constant [8].

Two improved ways of doing Williamson-Hall analysis which incorporate the anisotropic nature of the crystal into account are uniform deformation stress model (UDSM) and uniform deformation energy density model (UDEDM). In UDSM, the cause of anisotropic microstrain $\varepsilon_{\mathrm{hkl}}$ is assumed to be the uniform deformation stress $(\sigma)$ which has the same value in all crystallographic directions allowing density of deformation energy (u) to be anisotropic due to the anisotropic nature of modulus of elasticity. Microstrain along each crystallographic direction, $<\varepsilon_{\mathrm{hkl}}>$ is related to the uniform deformation stress, $\sigma$ as $\sigma=\mathrm{E}_{\mathrm{hkl}}<\varepsilon_{\mathrm{hkl}}>$ where $\mathrm{E}_{\mathrm{hkl}}$ is the Young's modulus along the [hkl] direction. Thus in UDSM, Williamson-Hall equation can be written as $\beta_{\mathrm{hkl}} \cos \theta_{\mathrm{hkl}}=(\mathrm{k} \lambda / \mathrm{t})+\left(4 \sigma \sin \theta_{\mathrm{hkl}} / \mathrm{E}_{\mathrm{hkl}}\right)$. By plotting $\beta_{\mathrm{hkl}} \cos \theta_{\mathrm{hkl}}$ versus $\left(4 \sin \theta_{\mathrm{hkl}} / \mathrm{E}_{\mathrm{hkl}}\right)$ the uniform deformation stress, $\sigma$ is obtained as the slope of the straight line fit while the crystallite size can be estimated from the Y-intercept $[6,12,13]$.

In UDEDM, the deformation stress $(\sigma)$ is assumed to be anisotropic while the density of deformation energy (u) is assumed to be uniform in all the crystallographic directions. 
According to the Hooke's law, the relation between energy density ' $u$ ' and the strain is given by $\mathrm{u}=\mathrm{E}_{\mathrm{hkl}}<\varepsilon_{\mathrm{hkl}}{ }^{2} / 2$. Therefore, Williamson-Hall equation in UDEDM model is written as $\beta_{\mathrm{hkl}} \cos \theta_{\mathrm{hkl}}$ $=(\mathrm{k} \lambda / \mathrm{t})+\left(4\left(2 \mathrm{u} / \mathrm{E}_{\mathrm{hkl}}\right)^{1 / 2} \sin \theta_{\mathrm{hkl}}\right)$. The plot is drawn between $\beta_{\mathrm{hkl}} \cos \theta_{\mathrm{hkl}}$ and $2^{5 / 2} \sin \theta_{\mathrm{hkl}} \mathrm{E}_{\mathrm{hkl}}{ }^{-1 / 2}$. The slope of the straight line fit gives $u$ and the $\mathrm{Y}$ - intercept correspond to crystallite size $[6,12,13]$.

For a given sample, Williamson-Hall analysis can be performed assuming the isotropic (UDM) and anisotropic models, viz., UDSM and UDEDM. From the correlation coefficients, R of the linear fits, the most suitable model in each case can be identified [6, 12-17]. Naturally, in most situations, models incorporating the anisotropic nature of the crystalline material are found to result in a better fit [6,12-17]. For example in the case nanocrystalline samples of AuxCu1-x and $\mathrm{Au}_{x} \mathrm{Ag}_{1-x}[13], \mathrm{Ag}[12]$, hydroxyapatite $\left(\mathrm{Ca}_{10}\left(\mathrm{PO}_{4}\right)_{6}(\mathrm{OH})_{2}\right)$ [17], $\mathrm{ZnO}$ [14-16], $\mathrm{NiO}[6]$ etc., UDEDM is reported to be the most suitable model.

There are two instances in which Williamson-Hall analysis provides physically meaningless results, viz. (i) negative $\mathrm{Y}$-intercept corresponding to a negative value for crystallite size and (ii) negative slope indicating a negative value for the r.m.s value of microstrain [36-39]. Negative value for microstrain implies a situation where microstrain causes narrowing of XRD lines which is physically impossible. A perusal of literature reveals that the negative slope is encountered most often in the case of samples with smaller crystallite sizes. Specific examples include reports on lead sulfide $\mathrm{PbS}$ (2 and $3 \mathrm{~nm}$ ) [40], ruthenium oxide $\mathrm{RuO}_{2}$ (12 and 18 $\mathrm{nm}$ )[20], zinc oxide $\mathrm{ZnO}\left(16\right.$ and $18 \mathrm{~nm}$ ) [3], lead molybdate $\mathrm{PbMoO}_{4}(14$ and $18 \mathrm{~nm}$ ) [41], nickel ferrite $\mathrm{NiFe}_{2} \mathrm{O}_{4}(13 \mathrm{~nm})$ [42] and nickel cadmium ferrite $\mathrm{NiCdFe}_{2} \mathrm{O}_{4}(17-20 \mathrm{~nm})$ [43]. If negative Y-intercept or slope is encountered it implies that the Williamson-Hall model is not suitable for modeling the combined contribution of small crystallite size and microstrain to the XRD line broadening [39]. 
For the Williamson-Hall analysis assuming UDSM and UDEDM, the elastic constants in each crystallographic direction is to be estimated. For cubic symmetry, the Young's modulus along the direction [hkl], $\mathrm{E}_{\mathrm{hkl}}$ is given as

$$
1 / E_{h k l}=s_{11}-\left(2 s_{11}-2 \mathrm{~s}_{12}-\mathrm{s}_{44}\right)\left(\mathrm{h}^{2} \mathrm{k}^{2}+\mathrm{h}^{2} \mathrm{l}^{2}+\mathrm{l}^{2} \mathrm{k}^{2}\right) /\left(\mathrm{h}^{2}+\mathrm{k}^{2}+\mathrm{l}^{2}\right)^{2}
$$

where $\mathrm{s}_{11}, \mathrm{~s}_{12}, \mathrm{~s}_{44}$ are the components of elastic compliance tensor $[44,45]$.

The components of elastic stiffness constants of $\mathrm{NiO}$ are $\mathrm{C}_{11}=316 \mathrm{GPa}, \mathrm{C}_{12}=56 \mathrm{GPa}$ and $\mathrm{C}_{44}=115 \mathrm{GPa}$ [46]. The elastic compliance components $\left(s_{\mathrm{ij}}\right)$ can be obtained from the stiffness constants $\left(\mathrm{c}_{\mathrm{ij}}\right)$ using the relations $\mathrm{s} 11=\left(\mathrm{c}_{11}+\mathrm{c}_{12}\right) /\left(\mathrm{c}_{11}-\mathrm{c}_{12}\right)\left(\mathrm{c}_{11}+2 \mathrm{c}_{12}\right) ; \mathrm{s}_{12}=-\mathrm{c}_{12} /\left(\mathrm{c}_{11}-\mathrm{c}_{12}\right)\left(\mathrm{c}_{11}+2 \mathrm{c}_{12}\right)$; $\mathrm{S}_{44}=1 / \mathrm{c}_{44}[44,45]$. Thus the components of elastic compliance of $\mathrm{NiO}$ are estimated as $\mathrm{s}_{11}=3.343 \times 10^{-3} \mathrm{GPa}^{-1}, \mathrm{~s}_{12}=-0.503 \times 10^{-3} \mathrm{GPa}^{-1}$ and $\mathrm{s}_{44}=8.696 \times 10^{-3} \mathrm{GPa}^{-1}$.

Williamson-Hall plots for representative samples N1, N4 and N6 assuming UDM, UDSM and UDEDM are shown in Fig. 2 and the results of analysis for all the samples are summarized in Table 1. For sample N1, all the three models show negative slopes which are physically meaningless. Williamson-Hall analysis can be done using integrated breadth instead of FWHM [31, 35]. Williamson-Hall plots for sample N1 using integral breadth instead of FWHM also resulted in negative slope (Fig. S1 in Supplementary material). Thus it is clear that conventional Williamson-Hall analysis is not working in the case of sample N1. For all other samples, the plots have positive slopes and Y-intercepts. The correlation coefficient, $\mathrm{R}$ for each fit is included in Table 1. Both the average crystallite sizes and microstrain values obtained using the three models are in agreement. It can be seen that for samples with relatively larger average crystallite size, $>15 \mathrm{~nm}$, the $\mathrm{R}$ values are large (> 0.95) while for sample N2, N3 and $\mathrm{N} 4$, the R values are comparatively small and fall in the range $0.44-0.78$. Further, from the R 
values no model among the three can be considered as performing better than the rest. This observation is in contrast with the reports in the case of cubic samples with metallic bonding such as silver [12], $\mathrm{Au}_{x} \mathrm{Cu}_{1-x}$ and $\mathrm{Au}_{x} \mathrm{Ag}_{1-x}$ [13], where the UDEDM performs markedly better than the other models $[12,13]$. In the case of $\mathrm{NiO}$, which also has cubic symmetry, the bonding is predominantly iono-covalent nature with some degree of directionality [47]. It is rational to infer that the nature of bonding, i.e., directional or not, also affect the performance of the Williamson-Hall models. Yogamalar et al. observed that all the three models perform equally well in the case of $\mathrm{ZnO}$ nanorods where the bonding is predominantly covalent in nature [18].

\subsection{Size-strain plot (SSP) analysis}

As already stated, a perusal of the available literature indicates that in the case of samples with very small crystallite sizes, the correlation coefficients of the fits are rather small for Williamson-Hall plots. Further, in many reports, a negative slope is encountered when the crystallite sizes are small, less than $20 \mathrm{~nm}$ [3, 20, 40-43]. Both these difficulties are encountered in the present study also as clearly evident from Fig. 3 and Table1. One possible reason for this could be the assumption that the crystallite size and microstrain contributions to line broadening are additive (i.e., $\beta_{\mathrm{hkl}}=\beta_{\mathrm{t}}+\beta_{\varepsilon}$ ) could be an over simplification and more complex convolution of the two contributions may be tried out.

The additive convolution of $\beta_{\mathrm{t}}$ and $\beta_{\varepsilon}$, i.e., $\beta_{\mathrm{hkl}}=\beta_{\mathrm{t}}+\beta_{\varepsilon}$ is most suitable for modeling the combined broadening due to small crystallite size and microstrain when both size and microstrain broadenings are closer to Lorentzian profile. However, this may not always be

correct. If the profiles are not Lorentzian and more Gaussian like, other convolutions are found to be more appropriate. In order to analyze the combined XRD line profile of symmetric peaks 
one simple method is to estimate the shape factor $\varphi=\left(\beta_{\mathrm{FWHm}} / \beta_{\text {int }}\right)$ where $\beta_{\mathrm{FWHM}}$ and $\beta_{\text {int }}$ are the full width at half maxima and the integral line breadth of a diffraction peak respectively. The Lorentzian and Gaussian limits for the shape factors are respectively 0.6366 and 0.9394 respectively [29]. Shape factor, $\varphi<0.6366$ and $>0.9394$ can be referred to as super Lorentzian and super Gaussian profiles respectively. If $\varphi$ lies in between the Lorentzian and Gaussian limits, it implies that the line profile is a convolution of Gaussian and Lorentzian profiles otherwise called Voigt. It is reported that when both the size and microstrain contributions have Lorentzian profile $\varphi$ will be close to the Lorentzian limit or will be super Lorentzian. In such cases, the simple additive combination of $\beta_{\mathrm{t}}$ and $\beta_{\varepsilon}$ will model the convolution very well [29]. As the shape factor moves away from Lorentzian to Gaussian limit, the simple additive combination may lead to less reliable or even physically meaningless results and other convolutions are to be tried out. Fig. 3(a) shows a plot of the shape factors for the three diffraction peaks for all the samples. The Gaussian and Lorentzian limits are also marked in Fig. 3(a) for convenience. It can be seen that the shape factors lie closer to the Gaussian limit or is super Gaussian in all the cases. Further, the average value of shape factors estimated using the three peaks for the samples are plotted in Fig. 3(b). It is clear that the average shape factor is closer to Gaussian limit than the Lorentzian limit. This explains why the performance of Williamson-Hall models assuming a simple additive combination of Lorentzian and Gaussian profiles was not suitable in the present case. Hence other convolutions of crystallite size and microstrain are to be tried out.

Another simple convolution possible for the size and microstrain contributions to line broadening is given by $\beta_{\mathrm{hkl}}{ }^{2}=\beta_{\mathrm{t}}{ }^{2}+\beta_{\varepsilon}{ }^{2}$ [48]. This convolution is based on the assumption that both the size and microstrain contributions respectively have Gaussian profiles [29, 48]. Substituting for $\beta_{\mathrm{t}}$ and $\beta_{\varepsilon}$ and rearranging, we get the expression, $\left(\mathrm{d}_{\mathrm{hkl}} \beta_{\mathrm{hkl}} \operatorname{Cos} \theta\right)^{2} / \lambda^{2}=$ 
$(\mathrm{k} / \mathrm{t})\left(\mathrm{d}_{\mathrm{hkl}}^{2} \beta_{\mathrm{hkl}} \operatorname{Cos} \theta / \lambda\right)+(\Sigma / 2)^{2}$. Here $\mathrm{d}_{\mathrm{hkl}}$ is the lattice distance between the (hkl) planes, $\mathrm{t}$ is the apparent volume weighted average size and $\Sigma$ is related to $<_{\varepsilon}>$ as $\Sigma=\left[2(2 \pi)^{1 / 2}\right]<\varepsilon>[48]$. This method which is referred to as the Size-Strain Plot (SSP) method has the advantage that more weightage is given to data from reflections at low angles, where the precision of the measurement is usually high [48]. By plotting $\left(\mathrm{d}_{\mathrm{hkl}} \beta_{\mathrm{hkl}} \operatorname{Cos} \theta\right)^{2} / \lambda^{2}$ vs $\left(\mathrm{d}_{\mathrm{hkl}}^{2} \beta_{\mathrm{hkl}} \operatorname{Cos} \theta / \lambda\right)$, the crystallite size and microstrain can be obtained respectively from the slope of the curve and Yintercept $[3,19,20,48,49]$. Size-strain plots for samples N1, N4 and N6 are shown in Fig. 4 and the results for all the samples are included in Table 1. It can be seen that the model works in a physically meaningful way for all samples including N1 as indicated by the positive slopes and positive Y-intercepts [48]. Further, the correlation coefficient of the fit is very high compared to the Williamson-Hall plots and is close to 1 for all the samples (Table 1). Thus it can be concluded that in the present case, the most suitable method is the size-strain plot method.

The study underlines the fact that the convolution of size and strain contributions to broadening assumed is very important in correctly interpreting the observed XRD line broadening of nanostructured samples. This is especially important in the case of samples with very small crystallite size. Another point to be noted is that the size-strain equation used does not takes into account the anisotropic nature of elastic constant. However, as the correlation coefficients for the fits are very close to 1 , an attempt incorporate the anisotropic nature was not attempted. As $\mathrm{NiO}$ has cubic symmetry anisotropy is relatively less while in the case of systems with less symmetric structures, the role of anisotropy may be more crucial. Hence the comparison of the performance of size-strain plot analysis and Williamson-Hall analysis for samples with less symmetric (more anisotropic) structures will be interesting. 


\subsection{Empirical dependence of crystallite size and microstrain on annealing temperature}

The crystallite size and microstrain values estimated using the size-strain plot together with those from Williamson-Hall plots are compared in Table 1. It can be seen that the strain values also show a regular decrease with increase in annealing temperature. This is due to the fact that by annealing in air/oxygen, the concentration of oxygen vacancies could decrease due to filling up of vacancies [50]. The source of microstrain in the samples is the presence of point defects, viz., both $\mathrm{Ni}^{2+}$ and $\mathrm{O}^{2-}$ vacancies and a decrease in the concentration of $\mathrm{O}^{2-}$ vacancies will cause a decrease in the microstrain [6].

The empirical dependence of average crystallite size and microstrain on annealing temperature is shown in Fig. 5 and are modeled using second order polynomial dependence [51]. The dependence of crystallite size on annealing temperature for the samples can be approximated by a second order polynomial, $t=-16.16+9.16 \times 10^{-2} \mathrm{~T}-5.63 \times 10^{-5} \mathrm{~T}^{2}$ where $\mathrm{t}$ is the average crystallite size and $\mathrm{T}$ is the annealing temperature in ${ }^{\circ} \mathrm{C}$. Solid curve in Fig. 5 is the polynomial fit as per the above relation. Further, the empirical dependence of microstrain on annealing temperature is given as $\left\langle\varepsilon_{\mathrm{rms}}\right\rangle=0.000463-9.76 \times 10^{-7} \mathrm{~T}+5.51 \times 10^{-10} \mathrm{~T}^{2}$.

\subsection{Estimation of lattice constant}

Rietveld refinements of the XRD patterns were done using General Structure Analysis System (GSAS/EXPGUI) suite program) using Fm3m (225) space group [52]. Results of the analysis for samples N1 and N4 are shown in Fig. 6. The background was modeled by shifted Chebyshev polynomials. Lattice parameter for single crystalline NiO is $4.177 \AA$ [JCPDS card No.47-1049]. The lattice constants for the samples N1 (4.184 ̊), N2 (4.183 ̊̊), N3 (4.180 ̊̊), N4 (4.177 $)$, N5 (4.177 $\AA)$, N6 (4.177 $)$ ) and N7 (4.177 $)$ ) obtained from the analysis are 
plotted in Fig. 7 as a function of the annealing temperature and the results are tabulated in Table 2.

A number of reports on the lattice expansion in nanocrystalline $\mathrm{NiO}$, with decrease in crystallite size had appeared in the literature [50, 53-56]. This is explained as due to a number of possible factors such as grain-surface-relaxation effect, formation of point defects, uncompensated Coulombic interactions, etc $[2,57]$. In the case of sol-gel derived nanostructured $\mathrm{NiO}$ samples, lattice constant is reported to decrease from 4.190 to $4.180 \AA$ when the crystallite size increase from 16 to $54 \mathrm{~nm}$ [51]. Peck and Langell had reported a decrease in lattice constant of $0.12 \%$ and $0.16 \%$ respectively for $\mathrm{NiO}$ samples with crystallite sizes 25 and $5 \mathrm{~nm}$ [57]. In the present case lattice expansion by $0.16 \%, 0.14 \%$ and $0.07 \%$, is observed for samples $\mathrm{N} 1$ (3.01 $\mathrm{nm}) \mathrm{N} 2(8.94 \mathrm{~nm})$ and N3 $(14.3 \mathrm{~nm})$ respectively. For samples N4 onwards with size greater than $16 \mathrm{~nm}$, the lattice constant is same as that for bulk. On comparing with previous reports it can be concluded that both large surface area to volume ratio and presence of defects contribute to the observed lattice expansion.

\subsection{Transmission Electron Microscopy (TEM)}

Fig. 8(a) and (b) shows the TEM image of samples N1 and N4 together with the selected area electron diffraction (SAED) patterns as insets. The particle size distribution can be approximated by a lognormal profile. The particle size estimated from the TEM analysis for samples N1 and N4 are respectively $2.3 \pm 0.9 \mathrm{~nm}$ and $14.4 \pm 0.2 \mathrm{~nm}$. The average particle size estimated from the TEM analysis is in good agreement with the average crystallite size estimated from XRD analysis for both the samples implying that the samples are monodispersed with minimum agglomeration. 


\section{Conclusion}

Nanostructured $\mathrm{NiO}$ samples were synthesized by the decomposition of carbonate precursor to obtain phase pure $\mathrm{NiO}$. The as prepared sample was annealed at different temperatures. Detailed analysis of the XRD line broadening reveal that size-strain analysis which assumes a different convolution of the size and microstrain contribution to XRD line broadening performs better than Williamson-Hall analysis assuming different models. In the case of sample with average crystallite size $\sim 3 \mathrm{~nm}$, Williamson-Hall models result in negative slope which is physically meaningless while size-strain plot method is found to be most suitable. Analysis of shape factor for the samples shows that the profiles are more Gaussian like which explains why the size-strain plot method is more suitable and Williamson-Hall equation which assumes Lorentzian profiles for both size and strain contributions lead to physically meaningless results. The study underlines the fact that the convolution of size and strain contributions to broadening is very important in correctly interpreting the observed XRD line broadening of nanostructured samples. This is especially important in the case of samples with very small crystallite size. An increase in crystallite size and decrease in microstrain with annealing temperature is also observed ad empirical relations for the dependence of crystallite size and microstrain on annealing temperature are obtained. Samples with average crystallite size less than $16 \mathrm{~nm}$ show lattice expansion. TEM analysis indicates monodispersed nature of the samples. 


\section{Acknowledgement}

K. Maniammal acknowledges Government of Kerala for Junior Research Fellowship under the

SC/ST development scheme. G. Madhu acknowledges University Grants Commission (UGC), Government of India for Financial Assistance in the form of FDP teacher fellowship. Authors gratefully acknowledge SAIF, IIT, Bombay for the TEM analysis and NIST (CSIR) Thiruvananthapuram for XRD measurements.

\section{Reference}

1. H. Gleiter, Prog. Mater. Sci.33 (1989) 223-227.

2. W. Qin, J.A. Szpunar, Philos. Mag. Lett. 85 (2005) 649-654.

3. A.K. Zak, W.H.A. Majid, M.E. Abrishami, R. Yousefi, Solid State Sci. 13 (2011) 251-256.

4. M.A. Krivoglas, K.P Ryaboshapka, Phys. Met. Metall. 15 (1963)14-26.

5. T. Ungar, Z. Kristallogr. suppl. 23 (2006) 313-318.

6. G. Madhu, V.C. Bose, K. Maniammal, A.S.A. Raj, V. Biju, Physica B 421 (2013) 87-91.

7. E. J. Mittemeijer, U. Welzel, Z. Kristallogr. 223 (2008) 552-560.

8. G.K. Williamson, W.H. Hall, Acta Metall. Mater. 1 (1953) 22.

9. B.E. Warren, B.I. Averbach, J. Appl. Phys. 21 (1950) 595-560.

10. R. Delhez, de Keijser, E.J.Mittemeijer, Fres. Z. Anal. Chem. 312 (1982) 1-16.

11. H. M. Rietveld, Acta Crystallogr. 22 (1976) 151-157.

12. V. Biju, N. Sugathan, V. Vrinda, S.L Salini, J. Mater. Sci. (2008) 1175-1179.

13. Y. Rosenberg, V.S. Machavariani, A. Voronel, S. Garber, A. Rubshtein, A.I. Frenkel, J. Phys. Condens. Matter. 12 (2000) 8081-8088. 
14. M.S. S. Saravanan, K. Sivaprasad, P. Susila, S.P. K. Babu, Physica B (2011) 165-168.

15. V.D. Mote, Y. Purushotham, B.N. Dole, J. Theor. Appl. Phys. 6 (2012) 1.

16. P.T. Garg, R. Rai, B.K. Singh, Nucl. Instrum. Methods Phys. Res., Sect. A. 736 (2014) 128134.

17. K. Venkateswarlu, A. Chandra Bose, N. Rameshbabu, Physica B. 405 (2010) 4256-4261.

18. R. Yogamalar, R. Srinivasan, A. Vinu, K. Ariga, A. C.Bose, Solid State Commun.149 (2009) 1919-1923.

19. A. Seetharaman, S. Dhanuskodi, Spectrochim. Acta, Part A.127 (2014) 543-549.

20. R. Sivakami, S. Dhanuskodi, R. Karvembu, Spectrochim. Acta A Mol. Biomol. Spectroc 152 (2016) 43-50.

21. S.G. Pandya, J.P. Corbett, W.M. Jadwisienczak, Physica E 79 (2016) 98-102.

22. K.H. Moon, Y.I. Kim, C.S. Park, Ceram. Int.42, Part B (2016) 1432-1438.

23. K.A. Aly, N.M. Khalil, Y. Algamal, Q.M.A. Saleem, J. Alloys and Compds. 676 (2016) 606612.

24. R. Newman, R.M. Chrenko, Phys. Rev. 114 (1959) 1507.

25. D. Adler, J. Feinleib, Phys. Rev. B 2 (1970) 3112-3134.

26. H. Sato, T. Minami, S. Takata, T. Yamada, Thin Solid Films 236 (1993) 27.

27. P. Lunkenheimer, A. Loidl, C. R. Ottermann, K. Bange, Phys. Rev. B 44 (1991) 5927.

28. D.S. Kim, H.C. Lee, J. Appl. phys.112 (2012) 034504.

29. J. I. Langford, D. Louer and P. Scardi, J. Appl. Cryst.33 (2000) 964-974.

30. V. Berkum, J. G. M. Delhez, R. de Keijser, Th. E. Mittemeijer, J Acta Cryst. A 52 (1996) 730. 
31. H.P. Klug, L.E. Alexander: X-ray diffraction procedures for polycrystalline and amorphous materials, 2nd edition, John Wiley and Sons, New York, (1974) p.642.

32. P. Scherrer, Gott. Nachr. 26 (1918) 98.

33. A.E. V. Arkel, Physica. 5 (1925) 208-212.

34. A. R. Stokes, A. J. C. Wilson, Proc. Phys. Soc. 56 (1944) 174.

35. W.H. Hall, Proc. Phys. Soc. A. 62 (1949)741.

36. C. Balasingh, A. Abuhasan, P.K. Predecki, Powder Diffr. 6 (1991) 16-19.

37. D. Balzar, In Defect and Microstructure Analysis by Diffraction, IUCr/Oxford University Press (1999). pp. 94.

38. S. Pratapa, B. O'Connor, B. Hunter, J. Appl. Cryst. 35 (2002) 155-162.

39. T. Ungár, G. Tichy and J. Gubicza, R. J. Hellmig, Powder Diffr. 20 (2005) 366-375.

40. S. B. Qadri, J. P. Yang, E. F. Skelton, B. R. Ratna, Appl. Phys. Lett. 70 (1997) 1020-1021.

41. V. M. Anandakumar, M.A. Khadar, phys. stat. sol. (a) 205 (2008) 2666-2672.

42. J. Jacob, M.A. Khadar, J. Appl. Phys. 107(2010) 114310.

43. B. P. Jacob, S. Thankachan, S. Xavier, E. M. Mohammed, Phys. Scr. 84 (2011)045702.

44. J.F. Nye, Physical Properties of Crystals, Oxford University Press 1964.

45. A. Cazzani, M. Rovati, Int. J. Solids Struct. 40 (2003) 1713-1744.

46. K.S. Upadhyaya, G.K. Upadhyaya, A.N. Pandey, J. Phys. Chem. Solids. 63 (2002) 127-133.

47. K. Matti, P. Mahadevan, D.D Sarma, Phys. Rev. B, 59 (1999) 12457.

48. M.A. Tagliente, M. Massaro, Methods Phys. Res., Sect. B. 266 (2008) 1055-1061.

49. S. P. Jahromi, N.M. Huang, M.R. Muhamad, H.N. Lim, Ceram. Int. 39 (2013) 3909-3914.

50. S. Deshpande, S.Patil, S.V.N.T.Kuchibhatla, S.Seal, Appl. Phys. Lett. 87 (2005) 133113. 
51. A.C. Gandhi, C.Y. Huang, C.C. Yang, T.S. Chan, C.L. Cheng, Y.R. Ma, S.Y Wu, Nanoscale Res. Lett. 6 (2011) 485.

52. A.C. Larson and R.B. Von Dreele, General Structure Analysis System (GSAS), Los Alamos National Laboratory Report LAUR (2004) 86-748.

53. M. Ghosh, K. Biswas, A. Sundaresan, C. N. R. Rao, J. Mater. Chem. 16 (2006)106-111.

54. W. J. Duan, S. H. Lu, Z. L. Wu, Y. S. Wang, J. Phys. Chem. C 116 (2012) 26043-26051.

55. D.P. Chen, X.L Wang, Yi Du, S. Ni, Z.B. Chen, X. Liao, Cryst. Growth Des.12 (2012) 28422849.

56. A. Kremenović, B. Jancar, M. Ristic, M. V. Vasic, J. Rogan, A. Pacevski, B. Antic, J. Phys. Chem. C, 116 (2012) 4356-4364.

57. M. A. Peck, M. A. Langell, Chem. Mater. 24 (2012) 4483-4490. 
Table. 1. Results of XRD analysis - Scherrer equation, Williamson-Hall analysis and the sizestrain plot analysis.

\begin{tabular}{|c|c|c|c|c|c|c|c|c|c|}
\hline \multirow{3}{*}{$\begin{array}{l}\text { Sampl } \\
\text { e Code }\end{array}$} & \multirow{3}{*}{$\begin{array}{c}\text { Size from } \\
\text { Scherrer eqn } \\
(\mathrm{nm})\end{array}$} & \multicolumn{6}{|c|}{ Williamson - Hall analysis } & \multirow{2}{*}{\multicolumn{2}{|c|}{ SSP }} \\
\hline & & \multicolumn{2}{|c|}{ UDM } & \multicolumn{2}{|c|}{ UDSM } & \multicolumn{2}{|c|}{ UDEDM } & & \\
\hline & & $\begin{array}{l}\text { size } \\
(\mathrm{nm})\end{array}$ & strain & $\begin{array}{l}\text { size } \\
(\mathrm{nm})\end{array}$ & strain & $\begin{array}{l}\text { size } \\
(\mathrm{nm})\end{array}$ & strain & $\begin{array}{l}\text { size } \\
(\mathrm{nm})\end{array}$ & strain \\
\hline N1 & $1.79 \pm 0.34$ & - & - & - & - & - & - & 3.01 & $\begin{array}{c}2.44 \times 10^{-4} \\
*(0.99)\end{array}$ \\
\hline $\mathrm{N} 2$ & $8.55 \pm 0.15$ & 9.19 & $\begin{array}{l}7 \times 10^{-4} \\
*(0.86)\end{array}$ & 9.91 & $\begin{array}{c}3.69 \times 10^{-4} \\
*(0.86)\end{array}$ & 10.1 & $\begin{array}{c}3.59 \times 10^{-4} \\
*(0.87)\end{array}$ & 8.94 & $\begin{array}{c}2.01 \times 10^{-4} \\
*(0.99)\end{array}$ \\
\hline N3 & $13.71 \pm 0.30$ & 14.5 & $\begin{array}{c}1.77 \times 10^{-4} \\
*(0.75)\end{array}$ & 14.5 & $\begin{array}{c}3.06 \times 10^{-4} \\
*(0.63)\end{array}$ & 15.1 & $\begin{array}{c}9.11 \times 10^{-4} \\
*(0.69)\end{array}$ & 14.3 & $\begin{array}{c}1.38 \times 10^{-4} \\
*(1)\end{array}$ \\
\hline $\mathrm{N} 4$ & $15.50 \pm 0.29$ & 17.1 & $\begin{array}{c}3.13 \times 10^{-4} \\
*(0.98)\end{array}$ & 17.1 & $\begin{array}{c}3.71 \times 10^{-4} \\
*(0.98)\end{array}$ & 18.3 & $\begin{array}{c}3.85 \times 10^{-4} \\
*(0.98)\end{array}$ & 16.0 & $\begin{array}{c}9.69 \times 10^{-5} \\
*(0.99)\end{array}$ \\
\hline N5 & $18.94 \pm 0.09$ & 21.9 & $\begin{array}{c}7.36 \times 10^{-4} \\
*(0.98)\end{array}$ & 21.9 & $\begin{array}{c}1.63 \times 10^{-4} \\
*(0.98)\end{array}$ & 21.5 & $\begin{array}{c}1.81 \times 10^{-4} \\
*(0.98)\end{array}$ & 17.4 & $\begin{array}{c}8.35 \times 10^{-5} \\
*(0.99)\end{array}$ \\
\hline N6 & $21.62 \pm 0.23$ & 23.9 & $\begin{array}{c}4.54 \times 10^{-4} \\
*(0.99)\end{array}$ & 23.9 & $\begin{array}{c}1.40 \times 10^{-4} \\
*(0.99)\end{array}$ & 22.3 & $\begin{array}{c}1.48 \times 10^{-4} \\
*(0.99)\end{array}$ & 20.4 & $\begin{array}{c}4.42 \times 10^{-5} \\
*(0.99)\end{array}$ \\
\hline N7 & $21.70 \pm 0.72$ & 24.8 & $\begin{array}{c}3.83 \times 10^{-4} \\
*(0.99)\end{array}$ & 24.8 & $\begin{array}{c}2.39 \times 10^{-4} \\
*(0.99)\end{array}$ & 24 & $\begin{array}{c}1.80 \times 10^{-4} \\
*(0.99)\end{array}$ & 21.3 & $\begin{array}{c}3.872 \times 10^{-5} \\
*(1)\end{array}$ \\
\hline
\end{tabular}

* $\mathrm{R}$ values of linear fit are shown in bracket. 
Table. 2. Results of Rietveld analysis of XRD pattern for annealed samples

\begin{tabular}{clllc}
\hline Sample code & Rp & Rwp & $\chi^{2}$ & Lattice constant $(\AA)$ \\
\hline N1 & 6.59 & 8.49 & 1.02 & 4.184 \\
N2 & 5.55 & 7.23 & 1.70 & 4.183 \\
N3 & 4.81 & 6.39 & 1.83 & 4.180 \\
N4 & 5.11 & 6.77 & 1.08 & 4.177 \\
N5 & 5.21 & 6.97 & 1.08 & 4.177 \\
N6 & 6.44 & 8.34 & 1.26 & 4.177 \\
N7 & 7.82 & 10.34 & 1.82 & 4.177 \\
\hline
\end{tabular}




\section{FIGURE CAPTIONS}

Fig. 1. X-ray diffraction patterns of nanostructured $\mathrm{NiO}$ samples.

Fig. 2. Williamson-Hall plots for samples N1, N4 and N6 sample using (a) uniform deformation model (b) uniform deformation stress model (c) and uniform deformation energy density model.

Fig. 3. (a). Variation of shape factor $(\varphi)$ with $2 \theta$ for the three diffraction peaks. The lines indicate Lorentzian and Gaussian limits (b). The average value of shape factor for the samples.

Fig. 4. Size - strain plots for samples N1, N4 and N6 samples.

Fig. 5. Variation of crystallite size and microstrain with annealing temperature.

Fig. 6. Result of Rietveld refinement of XRD patterns for samples N1 and N4

Fig. 7. Variation of lattice constant with annealing temperature.

Fig. 8. TEM images of samples N1 and N4. Insets show the SAED pattern and particle size distribution. 


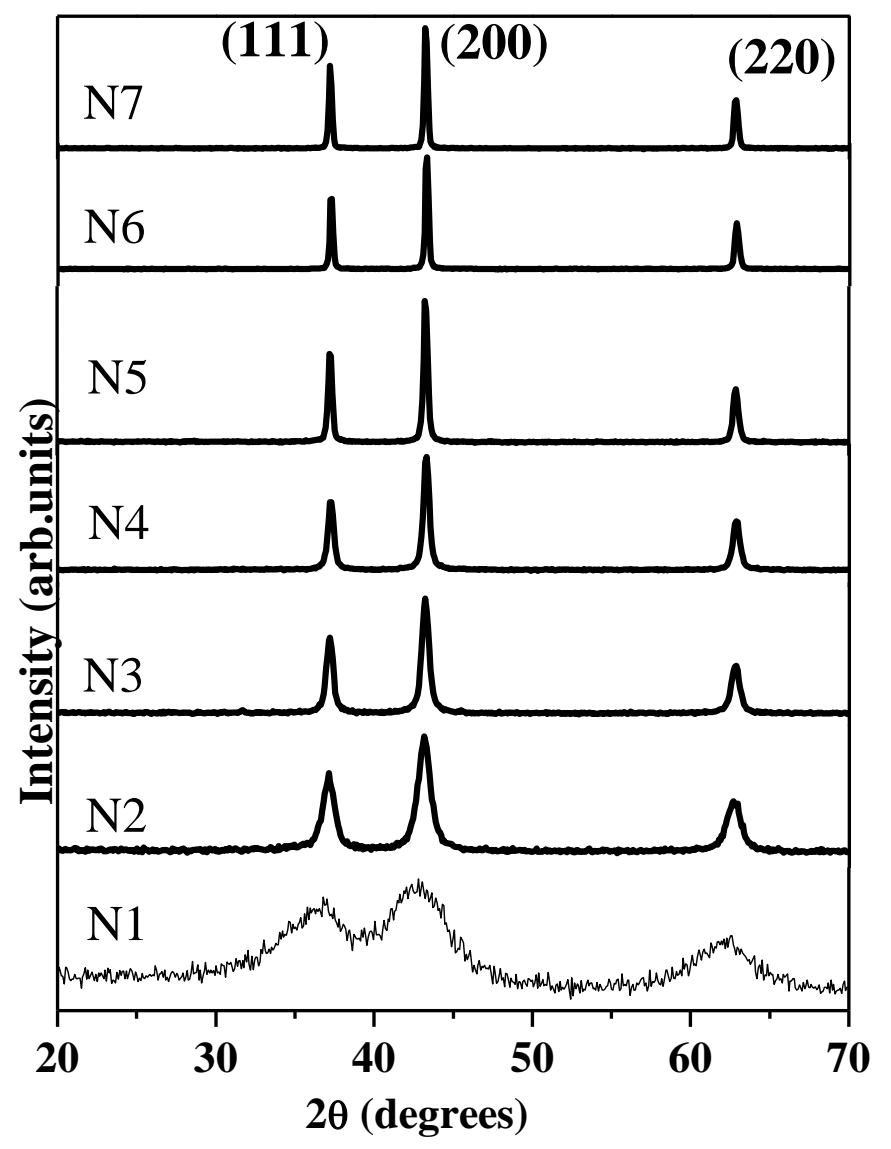

Fig.1. X-ray diffraction patterns of nanostructured $\mathrm{NiO}$ samples. 

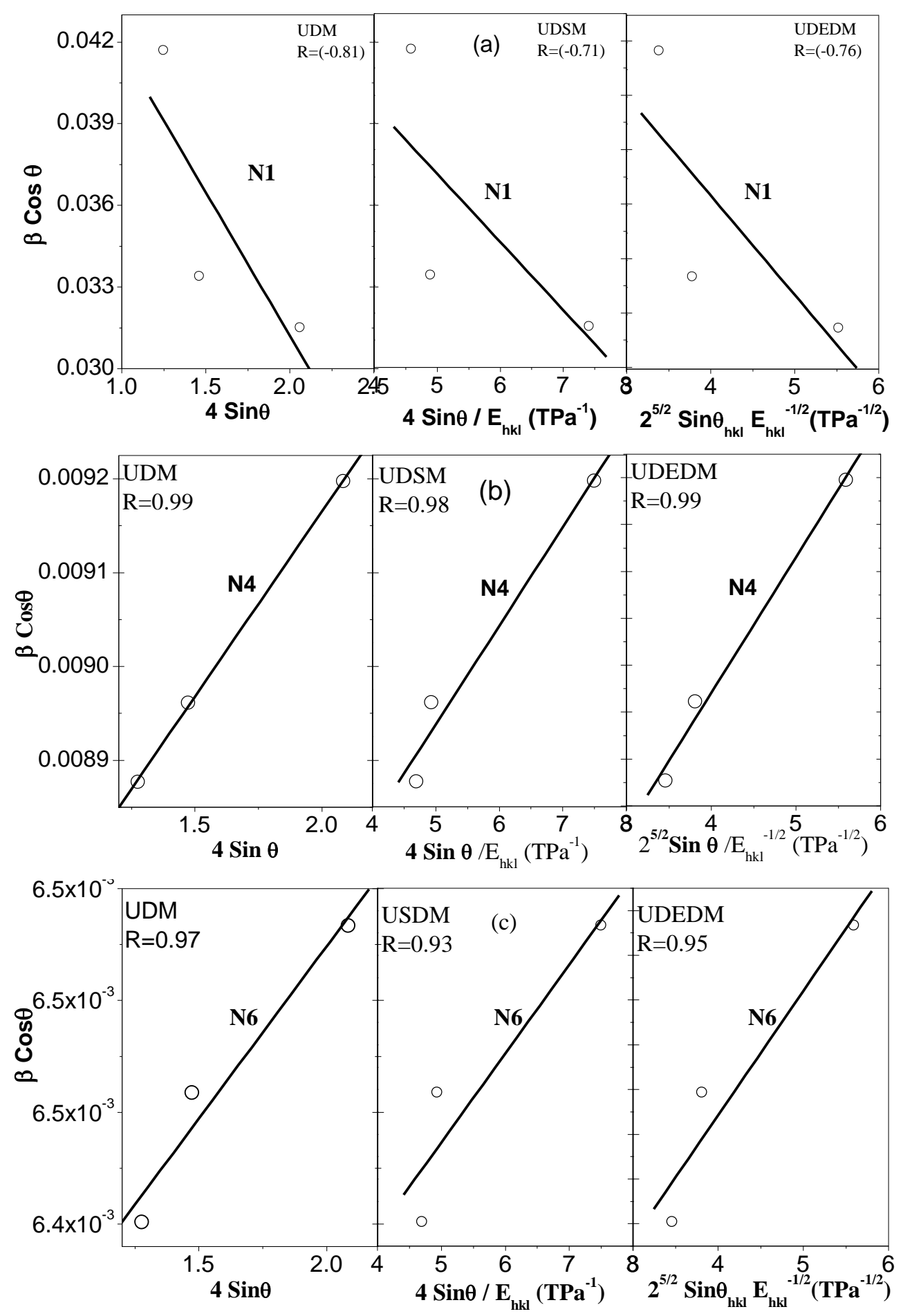

Fig. 2.Williamson-Hall plots for samples N1, N4 and N6 sample using (a) uniform deformation model (b) uniform deformation stress model (c) and uniform deformation energy density model. 

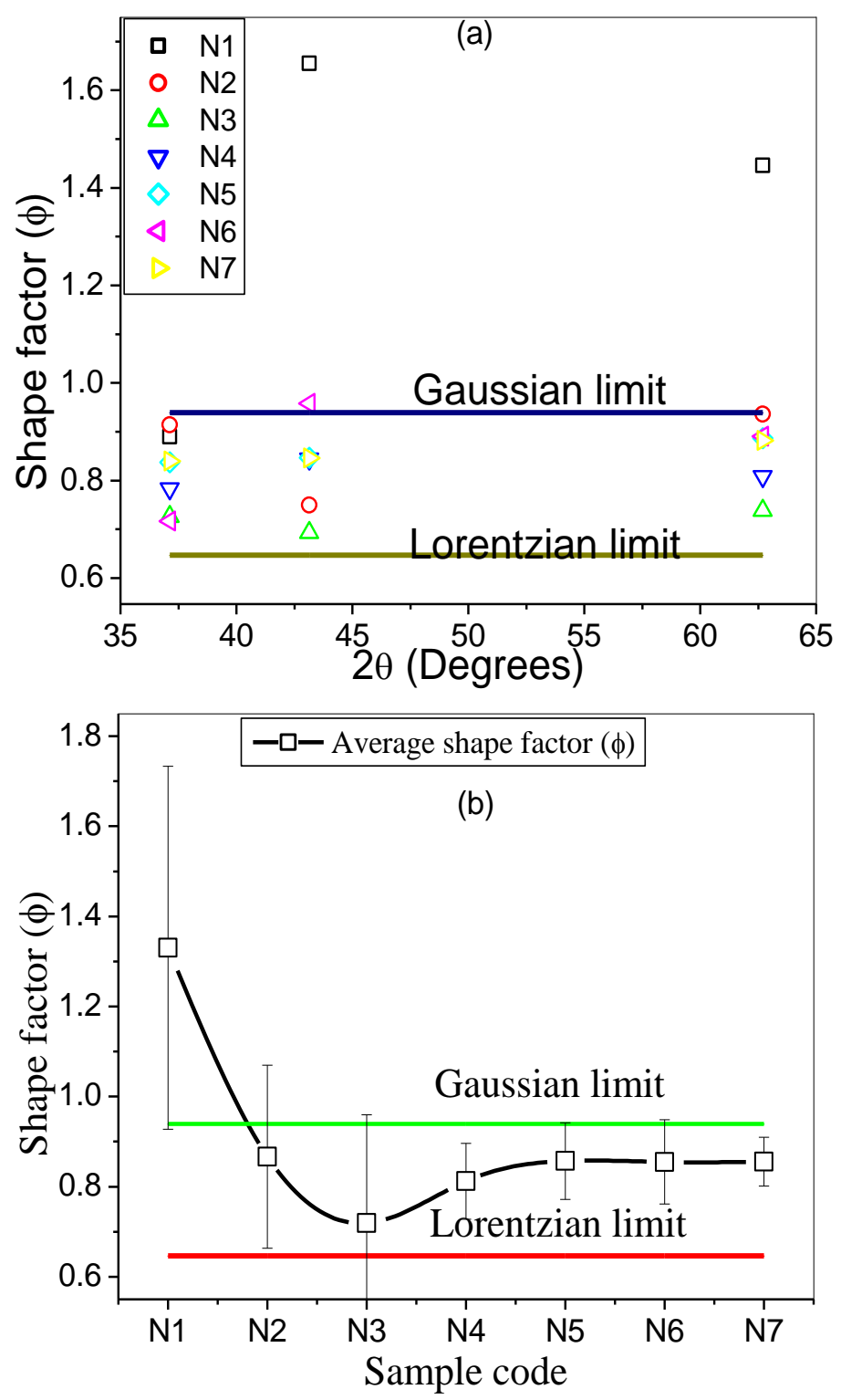

Fig. 3. (a). Variation of shape factor $(\varphi)$ with $2 \theta$ for the three diffraction peaks. The lines indicate Lorentzian and Gaussian limits (b). The average value of shape factor for the samples. 


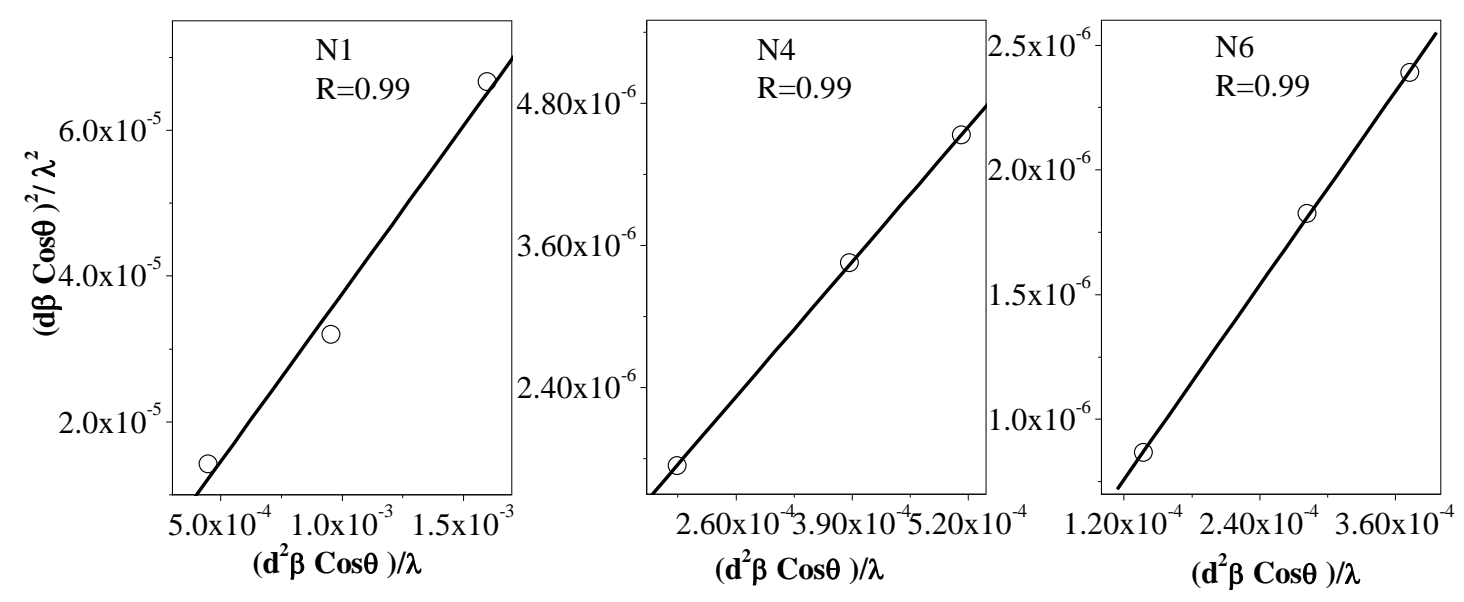

Fig.4.Size - Strain Plots for samples N1, N4 and N6 samples. 


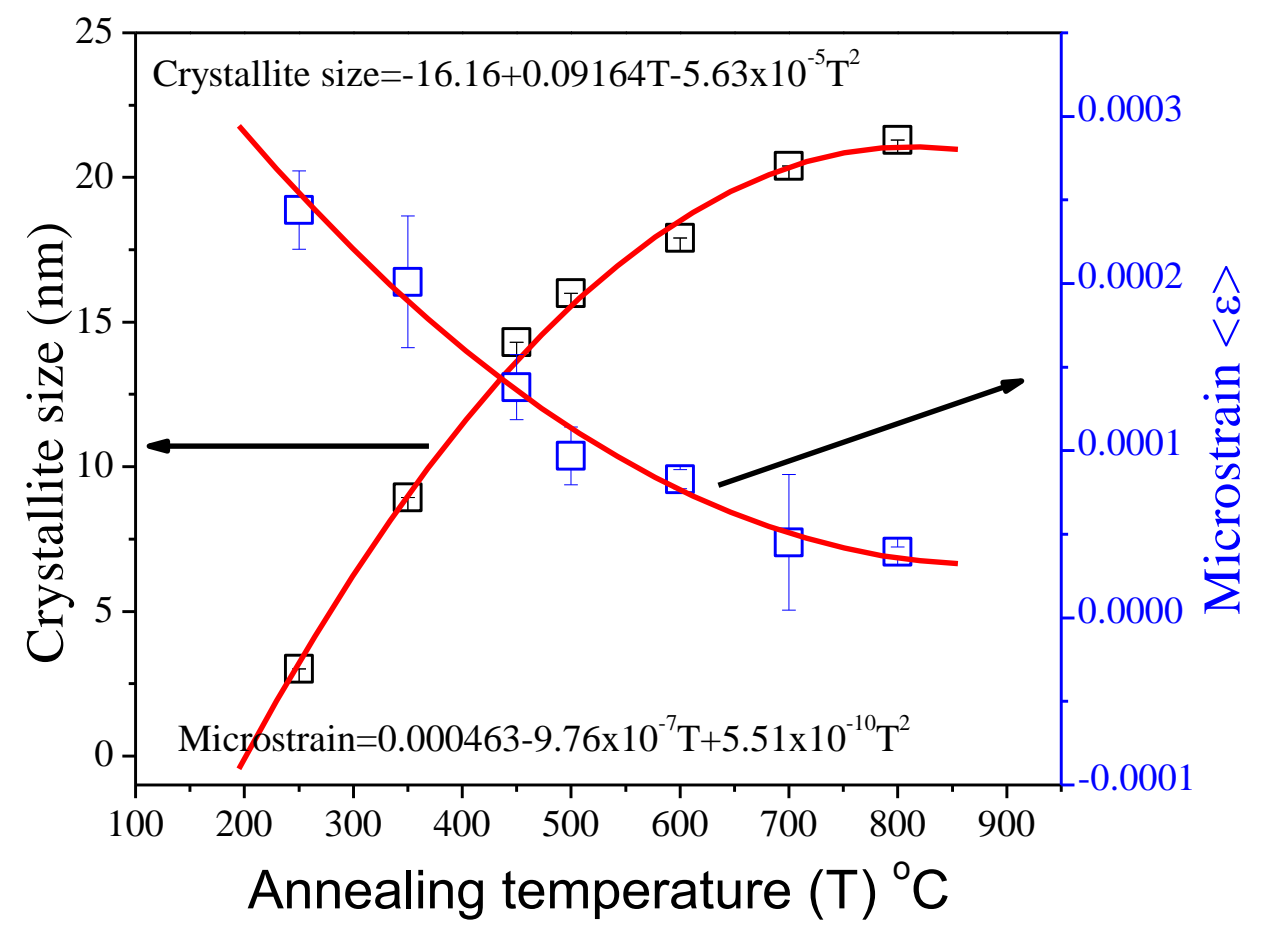

Fig.5. Variation of crystallite size and microstrain with annealing temperature. 

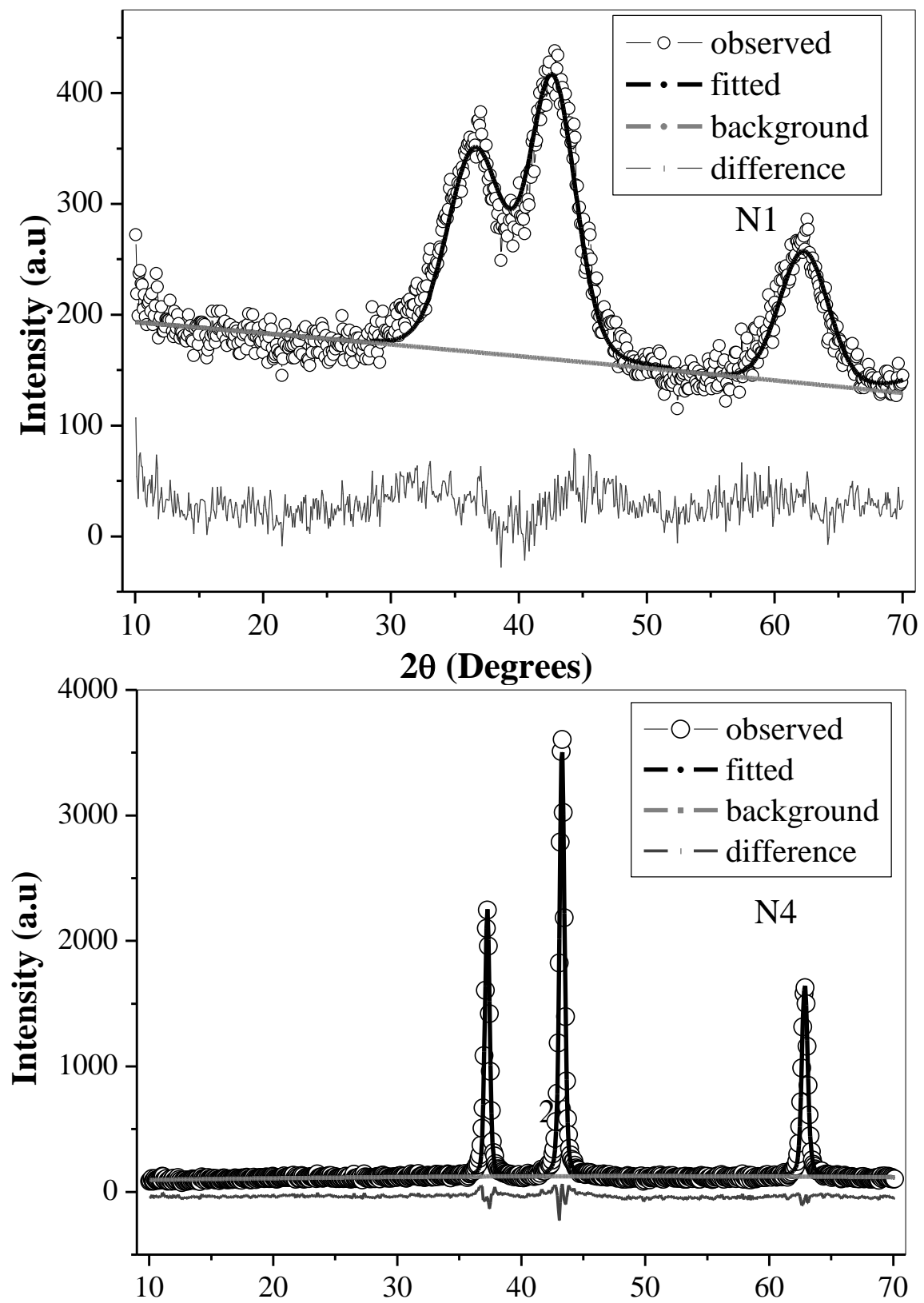
Fig.6.Result of Rietveld refinement of XRD patterns for samples (a) N1 and (b)N4.

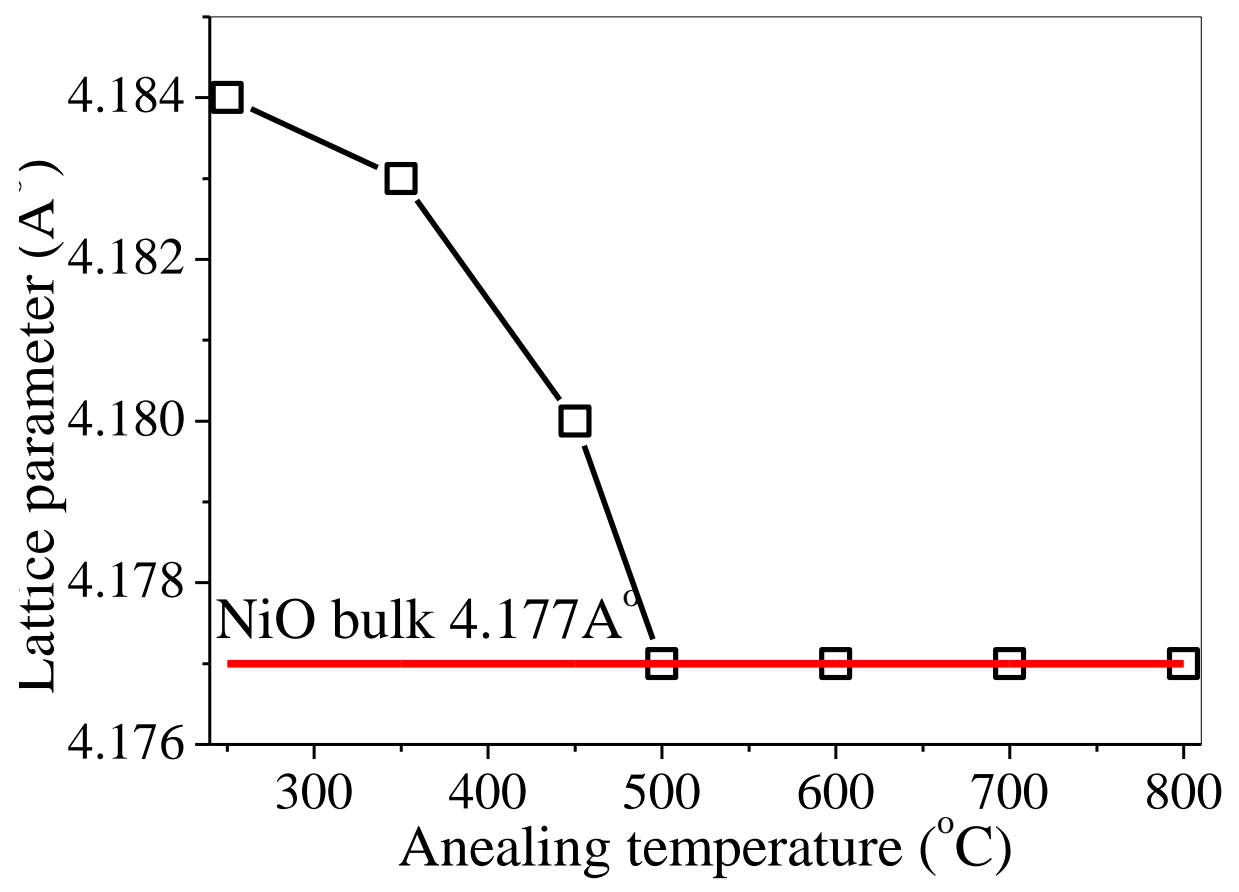

Fig.7.Variation of lattice constant with annealing temperature. 


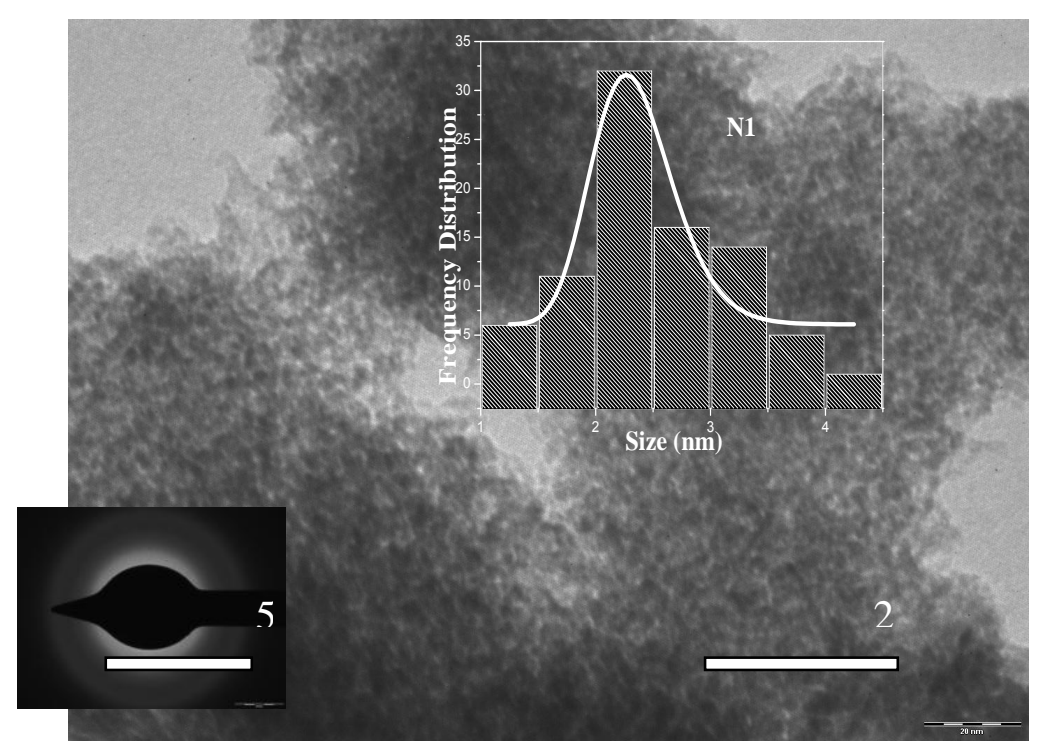




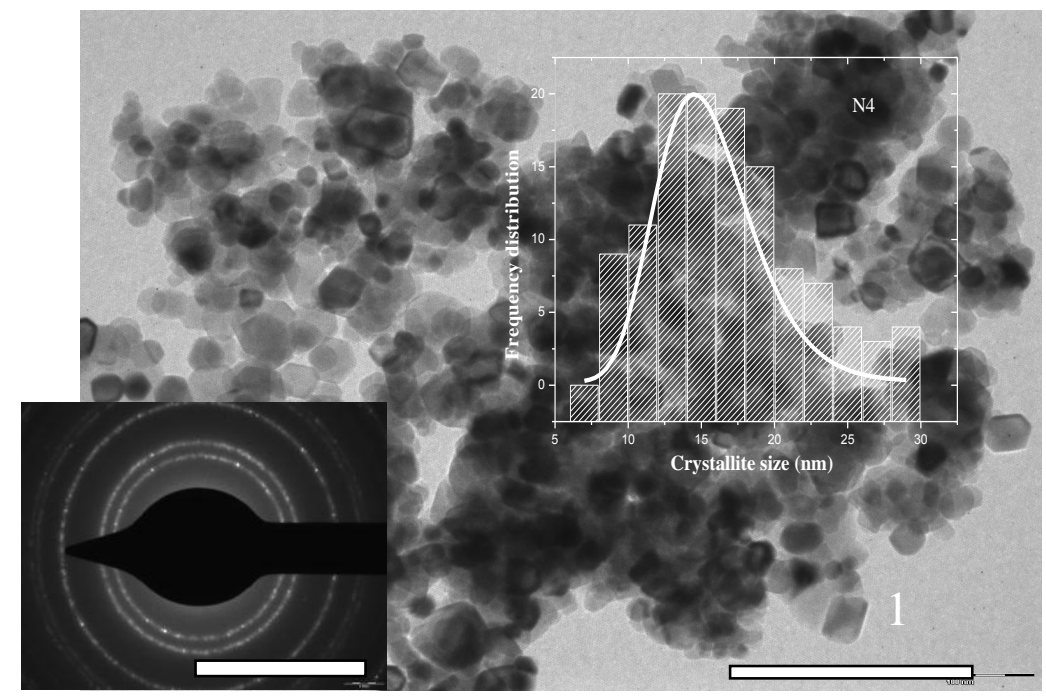

Fig .8. TEM image of nanostructured $\mathrm{NiO}$ samples (a) $\mathrm{N} 1$ and (b) N4. Insets show the SAED pattern and particle size distribution. 


\section{X-ray diffraction line profile analysis of nanostructured nickel oxide:}

\section{Shape factor and convolution of crystallite size and microstrain contributions}

K. Maniammal ${ }^{\mathrm{a}}$, G. Madhu ${ }^{\mathrm{b}}$, V. Biju ${ }^{\mathrm{a}, *}$

${ }^{a}$ Department of Physics, University of Kerala, Kariavattom Campus,

Thiruvananthapuram, Kerala, Pin - 695581, INDIA

${ }^{\mathrm{b}}$ Department of Physics, University College, Thiruvananthapuram, Kerala, Pin-695034,

INDIA

\section{GRAPHICAL ABSTRACT}

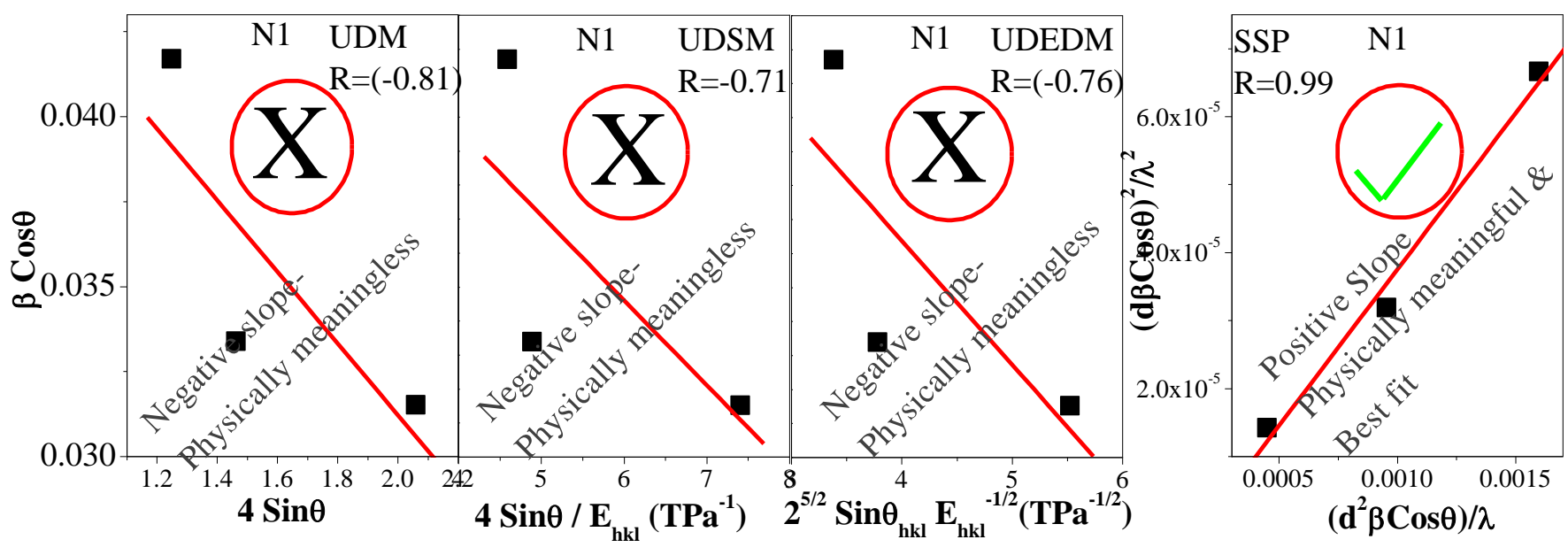

